\title{
Social work students' feedback about students' suitability for field education and the profession
}

\author{
Ines Zuchowski, Sally Watson, Tracey Dickinson, Nicole Thomas and Sandra Croaker \\ James Cook University, Townsville and Cairns, Australia
}

\begin{abstract}
INTRODUCTION: Many students successfully complete placement, while, for a minority of students, placement may be a time when questions are asked about suitability for placement and professional practice.

METHOD: Research undertaken with final year social work students examined their ideas about suitability and unsuitability for field education and practice and presented them with a model developed with field educators in an earlier phase of the research. The aim of the study was to incorporate students' understanding into the discourse of suitability/unsuitability to further develop a suitability/unsuitability model for collaborative discussions between students, educators and supervisors. Twenty-eight students responded to an online survey.
\end{abstract}

RESULTS: The results show that students identify a critical understanding of self, skills, knowledge, attitudes and contextual factors as important in assessing students' suitability for field education. Identified indicators of unsuitability included lack of preparedness to learn, lack of capacity to demonstrate an understanding of professional values and ethics and inability to maintain professional boundaries or demonstrate basic practice skills. Students overwhelmingly supported the use of the presented model and made suggestions for further development of the model.

IMPLICATIONS: The discussion emphasises the importance of using a pedagogically informed formative assessment strategy in a timely manner to address professional suitability with students.

KEYWORDS: Field education; suitability; students; assessment; values and ethics; social work education; social work practice

AOTEAROA

NEW ZEALAND SOCIAL WORK 31(2), 42-56.

CORRESPONDENCE TO: Dr. Ines Zuchowski ines.zuchowski@jcu.edu.au

\section{Introduction}

There has been significant research on student suitability for social work practice and field placement (see for example, Furness \& Gilligan, 2004; Lafrance \& Gray, 2004; Sussman, Bailey, Richardson, \& Granner, 2014). Much of this knowledge is derived from the perspective of field educators with little insight from the perspective of students. Students have unique perspectives on their learning, and they "... should be afforded opportunities to actively shape their education" (CookSather, 2006, p. 359). In the present study, students explored suitability and unsuitability for field education and practice and considered a model for discussion 
of student suitability and unsuitability developed in an earlier phase of the research with field educators (Croaker, Dickinson, Watson, \& Zuchowski, 2017).

\section{Background}

For social work students, field education is an important site for learning about professional practice. Social work educators, the professional social work association and practising social workers play a part in ensuring that students are ready for professional practice and, together, they take on a gatekeeping role for the profession (Bogo, Regehr, Hughes, Power, \& Globerman, 2002; Lafrance \& Gray, 2004; Sussman et al., 2014; Tam, Coleman, \& Boey, 2012).

While field education is a time for learning and growth, it may also be a time of associated stress. Stress can occur for students facing a required demonstration of their theoretical learning in practice and this experience can challenge students' sense of personal and professional identity (Homonoff, 2008).

Moreover, it can be difficult for students to undertake the required placement hours in light of multiple other demands, such as family obligations and work commitments (Agllias, Howard, Cliff, Dodds, \& Field, 2015). Field education can heighten the financial hardship experienced by social work students (Gair \& Baglow, 2017).

The great majority of students do well in field education, indeed, failing students in placement is difficult and unusual (Finch, 2017; Razack, 2000). Students' progress in field education is generally assessed via formative and summative assessment processes. Assessing students' performance against achieving outcomes or goals set in placement specific learning plans, agreements and contracts can provide a strong basis for assessing student suitability in field education and readiness for graduate practice (Cleak \& Wilson, 2019; Giles, Irwin, Lynch, \& Waugh, 2010). However, for assessment to be authentic it needs to consider the variable context of the placement, supervision and practice in which the student undertakes field education (Egan, Waugh, Giles, \& Bowles, 2017). Egan et al. (2017, p.738) present the following as key elements in assessment processes in field education: "identifying the learning challenge, linking it to the related professional practice standard, developing learning strategies to attain the standard, being explicit about the evidence on which the assessment will be based and contextual factors that affect the assessors decision". Giles et al. (2010) stress the importance of making the principles and strategies for assessment and evaluation transparent to facilitate collaborative reflection.

In the rare instances they occur, placement breakdowns can cause emotional stress for both students and field educators (Basnett \& Sheffield, 2010; Parker, 2010). Students have identified transparency, sharing of information and support from the university, as well as addressing power issues in the student-field educator relationship as important factors influencing their experience of the placement breakdown process (Parker, 2010). When difficulties arise in field education, locating the problems can be complex and field educators can question their own abilities in the process of failing a student (Basnett \& Sheffield, 2010).

Among the small cohort of students who struggle in field education, fail and / or need to repeat placements (Basnett \& Sheffield, 2010), sometimes concerns are raised about the overall suitability of the student for field education and/or the profession. Generally, placement breakdowns can be attributed to "not good enough learning", either because of circumstances or personalities (Giles et al., 2010). Failing placement is about the student not being ready to practice yet or in the future (Cleak \& Wilson, 2019). Placement has a gatekeeping role for the profession, and supervisors assess students' practice competence (Furness \& Gilligan, 2004). When suitability concerns are raised it is about students' overall fitness for practice (Furness \& Gilligan, 2004), as placements test their suitability for the social work career (Cleak \& Wilson, 2019). 
Field educators and social work educators can struggle to articulate professional suitability concerns clearly with students (Croaker et al., 2017; Finch, 2017), in part because suitability in social work is not easily defined. In the past, some have argued that unsuitability is somewhat pathological (Lafrance \& Gray, 2004). Similarly, others suggest that fixed personal attributes determine unsuitability for practice (Furness \& Gilligan, 2004).

Other authors argue that suitability is related to morals and virtues and students need to be supported in the curriculum to develop these characteristics (Holmstrom, 2014). Sussman et al.'s (2014) study about suitability / readiness for social work practice showed that field educators identified students' ability for conceptualisation and self-reflection as central to supporting the development of practice skills, personal attributes and professional practice. Tam et al.'s (2012) Canadian study identified indicators for professional suitability for social work practice relating to overall social consciousness, practice, and personal and ethical suitability. These indicators are reflected in the essential aspects of the assessment framework for field education

\section{Defining Suitability}

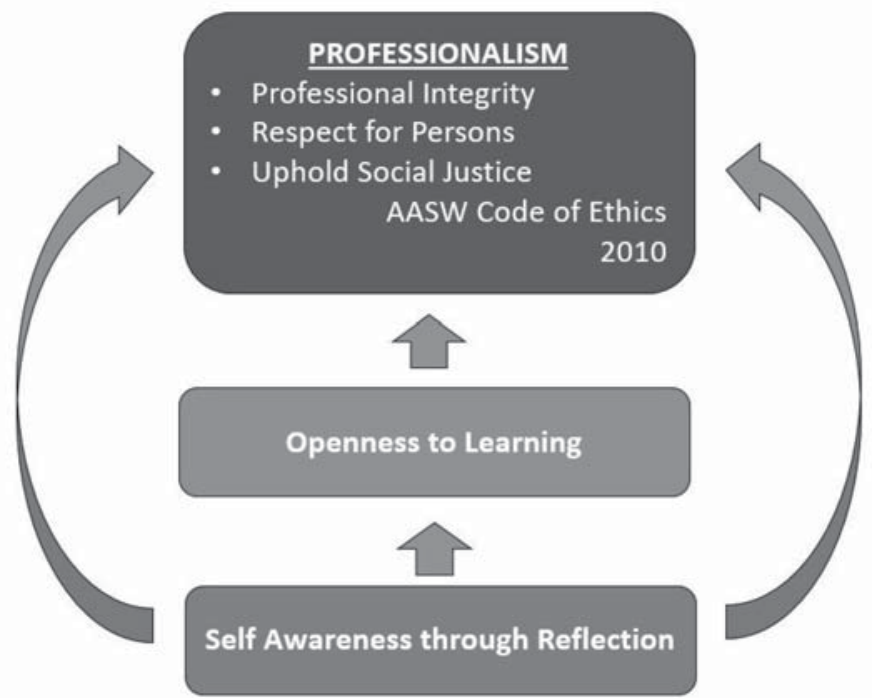

Figure 1. Model for defining suitability (Croaker et al., 2017, p. 117) developed by Egan et al. (2017, p. 738) which include "ethical practice, reflective practice, assessment, teamwork, interpersonal communication, community development, research, policy, organisational development and supervision".

Social work educators develop tools to measure student performance and competence against many of the authentic assessment concepts (Bogo et al., 2002; Tam et al., 2012). However, it is difficult to assess the non-academic elements of social work, such as attitudes, behaviours or beliefs. Cleak, Hawkins, Laughton, and Williams (2015) argue that education institutions predominantly rely on the practice wisdom and experience of field educators to assess these concepts. Similarly, McNamara (2013) points out that any assessment of students' performance in relation to concepts such as attitudes, behaviours or beliefs, significantly relies on individual supervisors' subjective assessment. The organisational background in which the field educator is placed has been found to influence their understanding of suitability (Lafrance \& Gray, 2004). To address these, and other issues associated with field educator assessments of student suitability, McNamara (2013) recommends that assessments are made jointly between the student, the field educator and the university liaison person, accessing a range of evidence.

The literature review highlights the centrality of field education in the professional degree. The student's learning experience on placement is impacted by the context of the placement, the supervisory relationship and the students' own skills and abilities. Failing students in field education is complex, and potentially reliant on subjective assessment. This Australian research builds on earlier work with field educators that resulted in the development of a model for defining suitability and unsuitability (Croaker et al., 2017).

Figure 1 highlights that self-awareness and reflective practice are critical to developing and upholding the ethics, values and standards for professional practice 
(Croaker et al., 2017). Field educators stressed the need for students to demonstrate an openness to learning on placement, such as being open to feedback, being pro-active in seeking learning opportunities and supporting interprofessional diversity in practice. They acknowledged that barriers to growth and personal learning for practice can be temporal and contextual (Croaker et al., 2017).

Figure 2 highlights that students deemed not suitable for social work practice are not able to "demonstrate key values, skills and knowledge required for practice", generally evidenced through lack of professional integrity, disrespect for persons or socially unjust practice (Croaker et al., 2017, p. 118). A key factor in determining unsuitability for practice was the lack of willingness or ability to utilise self-reflection in order to learn and / or develop self-awareness when issues of concern were identified (Croaker et al., 2017).
The focus of the concern was less on the assessment of whether a student passed or failed a placement against set assessment criteria, and more on engaging in discussion about suitability where supervision and feedback does not lead to critical reflection and personal/professional growth.

In this current phase of the research, final year social work students were asked about their understanding of what constitutes suitability and unsuitability for field education and practice and afterwards asked for specific feedback on the suitability and the unsuitability models presented in Figures 1 and 2. Suitability for field education and practice were presented as one concept, because suitability concerns relate to fitness and competence for practice, not just field education (Cleak \& Wilson, 2019; Furness \& Gilligan, 2004). This article presents the findings from this survey of final year students.

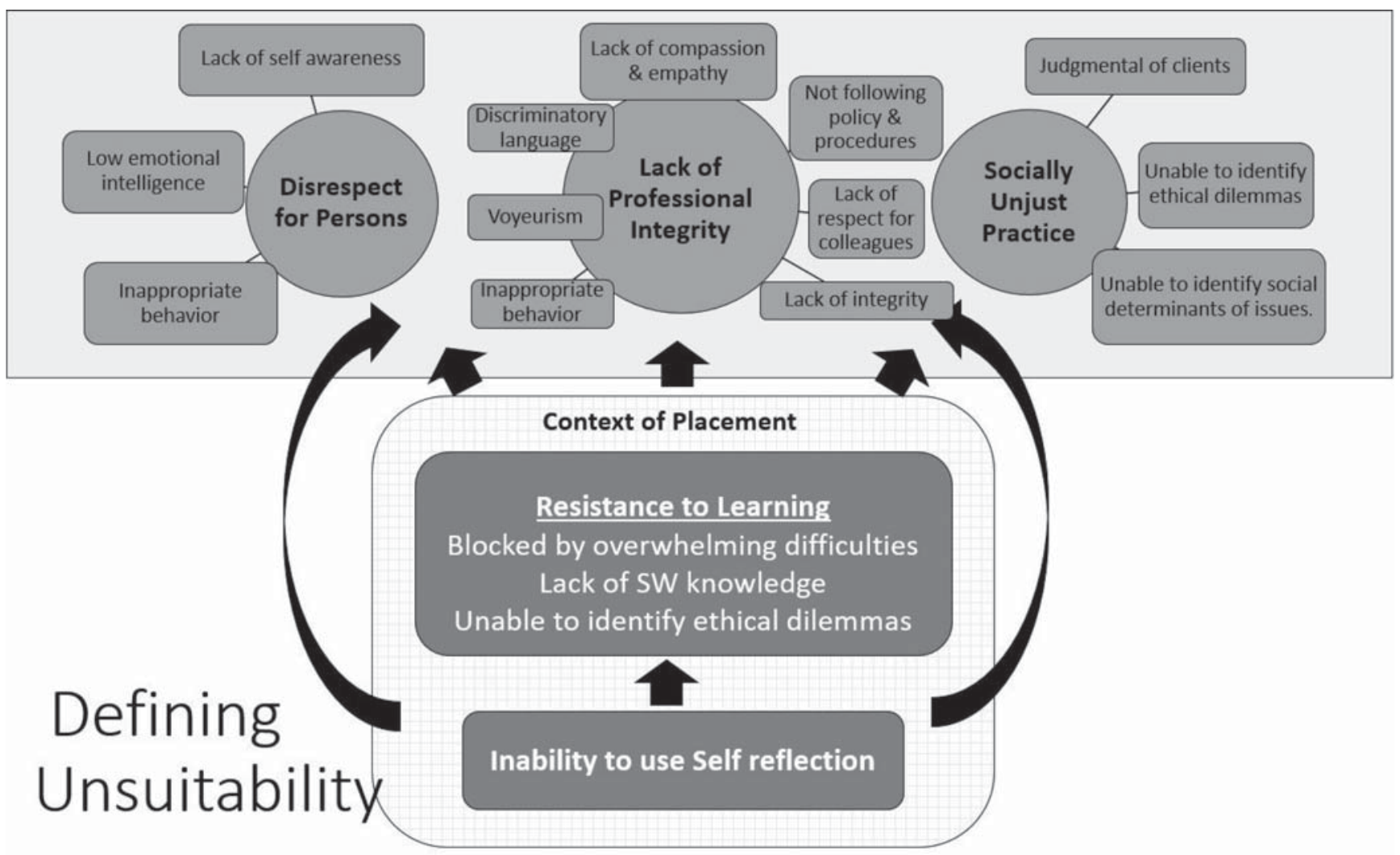

Figure 2. Model for defining unsuitability (Croaker et al., 2017, p. 118). 


\section{Methods}

The research was undertaken by the James Cook University social work field education team in conjunction with a final year social work student on placement. Four academics and one placement student conducted this research; all have authored this article. In 2017, an anonymous survey link was sent to 76 final year Bachelor of Social Work and Master of Social Work (PQ [Professionally Qualifying]) students enrolled in social work field education by the university's administration team. Survey Monkey software was used to support the data collection and analysis (Anderson \& Kanuka, 2003). Both qualitative and quantitative processes were used in the study. The study was approved by the university's Human Ethics committee.

The survey sought students' understanding of social work student suitability for practice as well as feedback on a suitability/unsuitability model developed in an earlier phase of the research (Croaker et al., 2017). The research questions posed were: What is students' understanding of student suitability and unsuitability for field education? What is students' feedback on the model developed with the field educators? The aims of the survey were to gain insights from students in order to check their understandings of suitability / unsuitability, to refine the model and to explore with students how this model might be applied in practice. In order to first gain an insight of students' understanding of suitability and unsuitability, the initial three, open-ended questions explored participants' ideas for student suitability, their prior use of models / frameworks for suitability and key indicators for suitability, before presenting the developed model.

Basic student demographics were collected, including gender, cultural background, degree studied, number of placements completed and number of placement breakdowns experienced. The survey was pilot tested by a potential respondent prior to its administration (Anderson \& Kanuka, 2003).
In total, $28(N=28)$ surveys were returned, resulting in a $37 \%$ response rate, however six of these were incomplete. All 28 respondents provided the following information in response to the first six questions of the survey: $93 \%(n=26)$ were female and 7\% (2) male; 7\% (2) were of non-English-speaking background; 57\% (16) of the respondents were enrolled in a Bachelor of Social Work degree and 43\% (12) in a Master of Social Work (Professional Qualifying) degree. In total, 79\% (22) had undertaken two placements, $18 \%$ (5) one placement and $4 \%$ (1) had not yet completed a placement.

Students were asked whether they had experienced a field placement break-down. Of the 27 respondents to that question, $15 \%$ (4) responded that they had, and 85\% (23) responded that they had not. One of the students who responded that they had experienced a placement breakdown did not complete any further questions. All of the students (4) who experienced a placement break-down had two placements, 75\% (3) were enrolled in a Bachelor of Social Work degree, and 25\% (1) in a Master of Social Work (Professional Qualifying degree). There were no significant differences in responses of the respondents who had experienced a placement break-down to those who had not.

The survey posed 17 questions in total; six of the 28 students did not respond to the remaining questions seven to 17 . Therefore, the overall survey response rate for question seven and beyond is $29 \%$.

\section{Data analysis}

The demographic data were analysed statically and summarised. The responses to the qualitative questions were coded by members of the research team and then analysed thematically, cross-checked and collaboratively discussed by the authors to ensure interrater reliability (Liamputtong, 2009). As a first step, individual researchers identified themes and compiled narratives 
from the findings in relation to each question. The narratives compiled for each question were then collated and analysed further. The research team, comprising of four field education academics and one student, developed a mind map to show aspects of the model that resonated with the students; aspects of the model that students identified as requiring further emphasis or elaboration; and new aspects suggested by the students.

\section{Results}

The findings highlighted that student ideas about suitability and unsuitability aligned with the models that had been developed with field educators. The findings were analysed and, through secondary analysis, linked to the topic areas in the presented model.

While the students' responses matched field educators' framing of suitability around professionalism, openness to learning and self-awareness through reflection (Croaker et al., 2017), the analysis of the student responses also highlighted the importance of contextual factors that need to be taken into account when considering suitability and unsuitability.

\section{Ideas about suitability and unsuitability}

Students were asked to consider suitability and unsuitability twice. Once generally, responding to an open question, "What do you consider important when thinking about suitability for social work field education experiences and/or professional practice?" and a couple of questions later, "What do you think are indicators of suitability for social work field placement/professional practice?" In total, 22 students responded to the initial question asking them what they considered important when thinking about suitability for social work field education and/or professional practice. All but one respondent listed more than one concept in their answers.
Initially, considering suitability for field education and/or social work practice, respondents listed a number of contextual factors relating to either their own personal circumstances, the supervisory relationship or organisational practice highly. Within the responses (26) pertaining to contextual factors, placement within an area of interest or passion as an important factor for suitability was mentioned 10 times. Previous experience (2), balancing placement hours with paid work requirements (2), self-care (2) and getting along with the Field educator (2) were also highlighted.

A further set of responses related to professionalism, such as demonstration of skills (2), knowledge (2) and values and ethics (5). Self-awareness, including understanding own values, flexibility and reflection was also rated as an important indicator of suitability by receiving a total of seven responses. Some students highlighted links between self-awareness and placement in an area of interest:

Knowing your area of interest and your inner self, needs, wants etc.

When asked specifically about indicators of suitability, responses were still similar, but the focus shifted more on professionalism, openness to learning and self-awareness. Column 4 of Table 1 highlights what students identified as the specific suitability indicators for social work field placement/ professional practice. A total of 22 students answered this question.

Overall, while there was still a focus on contextual factors, more students provided answers relating to professionalism, openness to learn and self-awareness. Contextual factors related to the placement organisation, field education delivery and support, and the student's personal circumstances accounted for a total of 22 responses. Apart from initiative $(n=4)$, which received the highest number of responses in this topic area, students identified a range of different indicators for suitability such as fit with 


\section{QUANTITATIVE RESEARCH}

Table 1. Student Responses Regarding Understanding Suitability for Social Work Field Education and/or Professional Practice

\begin{tabular}{|c|c|c|c|c|}
\hline $\begin{array}{l}\text { Topic area in } \\
\text { the presented } \\
\text { model }\end{array}$ & Considerations for suitability & $\begin{array}{l}\text { Number of } \\
\text { responses }\end{array}$ & Indicators for suitability & $\begin{array}{l}\text { Number of } \\
\text { responses }\end{array}$ \\
\hline \multirow[t]{3}{*}{$\begin{array}{l}\text { Contextual } \\
\text { factors }\end{array}$} & $\begin{array}{l}\text { Placement organisation - compatibility } \\
\text { with agency (1), location (1), }\end{array}$ & 2 & $\begin{array}{l}\text { Placement organisation - Tasks provided } \\
\text { (1), fit w agency (2), location (1) }\end{array}$ & 4 \\
\hline & $\begin{array}{l}\text { Field education delivery \& supervision - } \\
\text { getting along with } F E(2) \text {, enthusiastic \& } \\
\text { professional } F E(1)\end{array}$ & 3 & $\begin{array}{l}\text { Field education delivery \& supervision - } \\
\text { SV relationship (2) }\end{array}$ & 2 \\
\hline & $\begin{array}{l}\text { Student's personal circumstances - } \\
\text { interests (8), passion for profession (2), } \\
\text { previous experience (2), self-care (2), } \\
\text { balancing placement hours/paid work (2), } \\
\text { affordability (1), support (1), readiness (1), } \\
\text { maturity (2) }\end{array}$ & 21 & $\begin{array}{l}\text { Student's personal circumstances - } \\
\text { interests (3), previous experience (1), } \\
\text { self-care (2), balancing placement hours/ } \\
\text { paid work (2), initiative (4), getting out of } \\
\text { comfort zone (1), readiness (1), resilience } \\
\text { (1), maturity (1) }\end{array}$ & 16 \\
\hline Professionalism & $\begin{array}{l}\text { Ethics and values (5), skills (2), } \\
\text { knowledge (2) }\end{array}$ & 9 & $\begin{array}{l}\text { Values (5), skills (6), knowledge (4), ethical } \\
\text { decision making (2), understanding own } \\
\text { practice framework (1) }\end{array}$ & 18 \\
\hline $\begin{array}{l}\text { Openness to } \\
\text { Learning }\end{array}$ & $\begin{array}{l}\text { Open-mindedness (2), following } \\
\text { instructions (1), clear learning plan (1) }\end{array}$ & 4 & $\begin{array}{l}\text { Willingness to learn (3), openness to new } \\
\text { experiences ( } 7 \text { ) }\end{array}$ & 10 \\
\hline Self-awareness & $\begin{array}{l}\text { Self-awareness (2), understanding own } \\
\text { values (2), reflection (1), flexibility (2) }\end{array}$ & 7 & $\begin{array}{l}\text { Use of self (1), critical reflection ( } 7) \text {, open- } \\
\text { ness to feedback (1) }\end{array}$ & 10 \\
\hline
\end{tabular}

agency (2), the supervisory relationship (2), interest (3) and balancing placement hours and paid work (2).

Respondents' answers more clearly related to issues of professionalism when asked about specific indicators for suitability. The concepts listed related to social work values were: (5), application of social work skills (6) and knowledge (4), ethical decision making (2). Openness to learning (10), critical reflection and openness to feedback (10) were identified as a crucial indicator for suitability. For example, one student's response highlighted that:

A student needs to be willing to learn, open to new experiences and flexible with how they work.

Table 2 provides a summary of responses to a question asking students to outline indicators of unsuitability for social work field placement/ professional practice. Twenty-two students answered this question.
The most commonly suggested indicators of unsuitability focused on a lack of preparedness to learn (10); and a lack of capacity to demonstrate an understanding of professional values and ethics (8). A lack of preparedness to learn was described in various ways including:

Expecting others to direct your learning; and

Closed off to new learning, rigid thinking.

This lack of preparedness to learn was also described in conjunction with a lack of ability to reflect.

Other commonly suggested indicators of unsuitability included students" "inability to maintain professional boundaries" (5); and students" "inability to demonstrate basic practice skills" including communication and team work skills (5).

Four respondents suggested unsuitability for field placement should include a focus on 
Table 2. Indicators of Unsuitability for Social Work Field Education and/or Professional Practice

\begin{tabular}{|c|c|c|}
\hline $\begin{array}{c}\text { Overall topic area in the } \\
\text { presented model }\end{array}$ & Indicator of unsuitability & Number of responses \\
\hline \multirow[t]{2}{*}{ Contextual factors } & $\begin{array}{l}\text { Organisational barriers to demonstrating suitability } \\
\text { - } \quad \text { High turnover of personnel } \\
\text { - } \quad \text { Practice manuals missing } \\
\text { - } \quad \text { Working in a setting not interested in student/education } \\
\text { - } \quad \text { Not recognising student is a learner }\end{array}$ & 5 \\
\hline & Poor relationships & 2 \\
\hline \multirow[t]{4}{*}{ Professionalism } & Not demonstrating ethical standards or values & 8 \\
\hline & Inability to demonstrate practice skills & 5 \\
\hline & Student lack of preparedness and inexperience & 3 \\
\hline & Lack of social work knowledge & 1 \\
\hline Openness to Learning & $\begin{array}{ll}\text { Not being prepared to learn different ways of working } \\
\text { - } & \text { Resistance to learning } \\
\text { - } & \text { Rigid thinking } \\
\text { Inability to reflect }\end{array}$ & 10 \\
\hline \multirow[t]{2}{*}{ Self-awareness } & Inappropriate use of self & 5 \\
\hline & Not understanding supervision & 1 \\
\hline
\end{tabular}

barriers to demonstrating suitability presented by the placement organisation, including:

- consideration of the unsuitability of practice areas / organisations due to conflict with a particular student's personal values, experiences and / or interests (2); and

- consideration of whether a placement site offers sufficient recognition of and opportunity for student learning.

\section{Prior use of frameworks to consider suitability}

Respondents were asked whether they had used any framework, model or other process to consider their suitability for field education and/or professional practice. In total, 22 respondents answered the question; of these $27 \%$ (6) responded in the negative. The majority of the respondents could identify models, frameworks and ways of thinking that they had applied in considering their suitability for field education and/or professional practice. Most commonly they identified that they had used social work knowledge or models; 36\% (8) outlined social work theories, models and values as reference points. One participant, for example highlighted:

[I] often engage in critical reflection and have benefited from this especially when receiving supervision on placement.

I also think that just being involved in the education process can be an indicator of how well you align with the professional values.

A number of participants indicated that their area of interest (3) and their compatibility with the organisation (2) influenced their thinking about their suitability for placement or practice. One respondent, for example outlined:

Yes and no. My framework for practice has changed to suit the organisational capability frameworks to some extent 
which supports the idea that it can be situationally interpreted.

\section{Suggestions for developing the presented model further}

Respondents were presented with Figure 1 and Figure 2 in separate questions and asked: (i) whether they thought the student suitability/unsuitability model for field education and or professional practice would be useful, (ii) whether anything needed to be added to or deleted from either model; and (iii) why, or why not?

The majority of the respondents thought that the model developed for exploring suitability was useful and recommended the use of the model early in their degree. They also highlighted that they would want to have any concerns about their suitability raised early in their field education experience, presumably to allow them time to address such concerns.

Of the 22 respondents to the question about whether the model would be useful, $86 \%$ (19) thought this model was useful, 5\% (1) did not indicate either support or rejection and $9 \%(2)$ responded in the negative. Of those who thought the model would be useful, 55\% (11) provided no further comment or indicated general support for the elements included in the model and $27 \%$ (6) commented it looked simple, clear and/ or easy to use, including as a mechanism to:

\section{Help student(s) understand their role.}

Two respondents who thought the model would be useful suggested a focus on students' ability to "work" in an organisation and another respondent suggested the model required further elaboration.

The two respondents who indicated the model would not be useful offered the following reasons:

I believe we are always open to learning, but some organisations do not have SW opportunities.
(It) fails to recognise reality and complexities of what students go through when being placed in to agencies to complete unpaid placements as powerless units with minimal to no rights.

Similarly, of the 22 respondents who answered the question on whether the unsuitability model was useful: $90 \%$ (20) thought it was, 5\% (1) did not indicate either support or rejection and 5\% (1) responded in the negative. The majority of students (16) who responded that the framework was useful also commented that they found the framework reflected their knowledge of unsuitability suggesting that it was "a thorough diagram of unsuitability" and "practically covers everything". A number of respondents (10) commented that the diagram was "clear" and "easy to follow".

One student identified the framework as problematic and another as limited. One suggested that unsuitability "is not necessarily around basic SW values". Both students wanted alternative explanations for a possible unsuitability evaluation of the student: one suggested the fact that "some people do not fit with specific organisations" needed to be reflected in the framework and the other identified the framework as a "classic blame the victim model".

\section{Suggestions for using the suitability model with students}

Out of the 21 responses to the question about how students would use the suitability model in the future, $81 \%$ (17) stated that they would use it: to address or articulate aspects of their practice, measure the quality of their work, in preparation for placement and as a reflective tool. Respondents' comments included:

It's a good visual to encourage thoughtfulness around these key skills.

I believe they could also serve as a helpful tool in being able to articulate the profession to others. 
Two people expressed that they would not use the framework in the future. One did not comment further and the other stated that they perceived the framework to be one-directional, and heavily skewed as a university-serving model.

The majority of respondents (13) suggested that the presented model could be a useful tool to facilitate such a conversation and/ or to facilitate a shared understanding of the issues at hand. Comments included:

Yes, it could provide a visual, objective framework to use to describe any challenges being experienced.

This framework can help both parties have a good understanding of the importance of the student having professional practice and can provide a guideline to any concerns either party may have.

Further, respondents suggested that the model could be used as a tool for facilitating critical reflection and to identify key practice challenges facing the student. One student suggested that the framework could also be used to identify more contextual issues pertaining to the placement, including other staff's behaviour towards the student, "as the student would not be able to highlight behaviours of individuals within the organisation they are placed with that doesn't sit well with them."

The overwhelming response to the question of how students would like field educators or liaison staff to engage with them if concerns about suitability were identified was that this should be addressed directly with them (17). This was often linked to the concepts of honesty (5), timeliness (4) and communication (3). The following response summarises the overall sentiment well:

To be honest with their concerns. Direction and clear communication is key. We are the students in the end. We need guidance from professionals, even if it means identifying concerns with our suitability.

A number of respondents (4) highlighted that the manner feedback is given is important, as indicated in the following comment:

Affirming the student not framing it as a personal attack. Focus on skills that might be missing more than personal qualities. Being polite, considerate and kind in their delivering of feedback.

Of particular interest is that five of the 21 respondents to this question suggested that the described model for suitability should be used more broadly across the social work course including prior to field education. For example, one suggested that:

...this framework could be used in marking $2 \mathrm{nd}$, 3rd and 4 th year assignments, added to the rubric to help student see their strengths or understand areas for improvement, which would support understanding regarding suitability.

\section{Extending the model}

Students' responses regarding suitability and unsuitability more strongly focused professionalism, openness to learn and self-awareness after they considered what might be specific indicators. Even though the focus on contextual factors as determining elements of suitability for placement and / or practice remained at a similar level, students also clearly located professionalism as an important indicator for suitability. The responses relating to professionalism increased by $100 \%$, openness to learning by $150 \%$ and self-awareness increased by $75 \%$ when considering indicators for suitability.

Nevertheless, contextual issues continued to be important issues in the students' responses. Figure 3 shows how the student feedback affirms ideas about suitability 


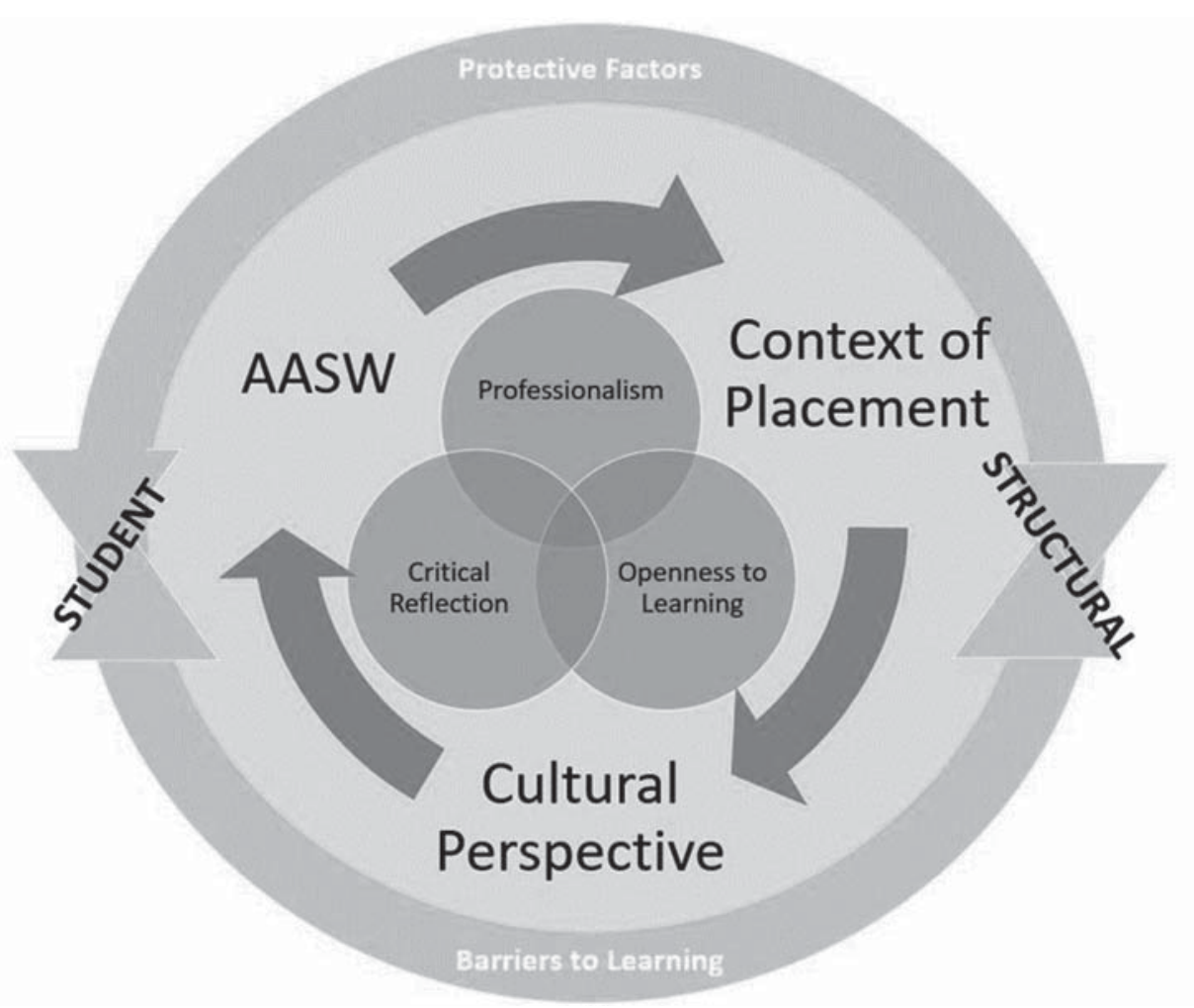

Figure 3. The context of exploring suitability.

developed with field educators, but extends and complement the model to capture the challenges presented within the placement context, personal and structural barriers that my influence the students' ability to demonstrate suitability. The new model equally considers placement preparation, support and discussions alongside a focus on professionalism, self- awareness and openness to learning. Placement context issues can be interpreted broadly although students identified sub-standard field education programmes, non-compatible supervisory relationships or agency environments and personal challenges. In developing the new model of suitability, the diagram illustrates how the context of a student placement can influence a negative assessment of student suitability, yet does not pre-determine the outcome of the student experience.

Placement context and student strengths are also acknowledged as possible protective factors for students on placement (AASW, 2013). Field education preparation, embedded field placement support processes, effective supervisory relationships, student skills, knowledge and experiences, and their understanding of their learning needs are all considerations and tools in addressing challenges within the placement. The new model illustrates how student suitability is influenced by positive and negative contextual issues.

Supervision with students can actively explore the student's learning experience and journey to professional practice in the context of the structural barriers that might impact their learning journey, the protective factors that can be put in place and any aspects that shape the supervisory relationship, the organisation and the student placement. The aim is to provide a placement environment that is spiritually, emotionally and socially safe (Cleak \& Wilson, 2019), one in which students can 
explore suitability for, and progression to, professional social work practice.

Placement contextual issues have the potential to significantly undermine the placement experience of the student if not considered by the organisation and / or the university in planning and supporting the placement. Overall, suitability for placement considerations connect to the field education programme, organisational factors, the student experience and learning needs and how well the university has introduced suitability throughout the degree.

In this Australian study, the guidelines of the Australian Association of Social Work have been referred to. However, these are in line with the global definition of the social work profession issued by the International Federation of Social Work (2014) and the implicit core mandates of promoting social change and empowerment, and core principles of respect, dignity and upholding human rights and social justice, social work theories and science, to guide social work practice in Australia and elsewhere.

\section{Discussion}

This research has highlighted the importance and value of seeking student input into discussion on suitability for practice in the context of the delivery of social work education. It provided useful information to confirm and extend the model beyond students' individual attributes to the consideration of contextual factors, but also affirmed the usefulness of using this model for discussions about students' suitability for social work practice early in the degree. Students clearly identified indicators of suitability as located in the areas of contextual factors, professionalism, self-awareness and openness to learning, the correlation/interrelation of these areas and their equal importance in relation to determining suitability for placement/ professional practice.
Student responses showed that they considered professionalism, openness to learning and self-awareness even before being presented with the model that had been developed with field educators and that the model developed with field educators has relevance to them. This is an encouraging result for social work education. In engaging students in research about educational practices, we are preparing future practitioners to be active and engaged learners. Moreover, listening to student voices includes students' views as a legitimate perspective in educational practices (Cook-Sather, 2006).

Prior work highlighted the importance of transparent principles and strategies for assessment facilitating collaborative discussion and critical reflection (Cleak \& Wilson, 2019; Giles et al., 2010). The findings here highlight that most students support the use of explicit models and methods for discussion of suitability and unsuitability for social work field education and practice. The model offers students a practical tool to facilitate collaborative discussion and critical reflection in order to consider ethical approaches to practice, meet the expected standards of practice and become practitioners (Giles et al., 2019). Students also recommended early proactive engagement in discussions around suitability on their journey to professional social work. This suggests discussions about suitability need to occur early in the degree, not just in association with placement.

Finally, students suggested consideration of contextual issues when suitability concerns are raised with them. Without doubt, contextual factors can shape, facilitate and limit social work practice and education, such as pressured workplaces or financial hardships of students (Agllias et al., 2015; Gair \& Baglow, 2017). What the current findings have further highlighted is that the contextual frame of the placement experience, such as organisational issues are central to students' experiences and thus need to be overtly discussed in 
setting up placement opportunities and reviewing performance in field education. In this light, more explicit recognition of contextual factors involving structural barriers, organisational shortcomings and students' practice aspirations are important considerations in order to avoid "blaming the victim" and/or being too heavily skewed towards "serving university purposes".

This focus on contextual factors needs to also take into account that working with students in social work field education programmes is impacted by education becoming a commodity (Olssen \& Peters, 2005). Students paying to undertake a 500 hours placement expect a good product. For some students this is shaped by pre-conceived ideas of what is a good placement including what might lead to the employment outcomes they hope for at the end of their degree. As a result, it can be speculated that suitability for students can be about the placement suiting them. It would appear that such a perception of suitability being connected to student interests and preferred fields of practice could inhibit students' ability to appreciate the significant learning opportunities various placement opportunities may offer them. This is addressed to some extent by the inclusion of openness to learning as an essential element in the suitability model. However, a tension is that students make many sacrifices in order to undertake a placement, including experiencing additional financial hardship during placement (Gair \& Baglow, 2017), and additional work, life, family balance pressures (Agllias et al., 2015). In this context, it is understandable that some students might feel let down by social work education, a sense of double betrayal: the placement may not meet the expectation of a good product and the impact of their adjustments and sacrifices to undertake placement may not be recognised. This could foster an environment of frustration which may impact on professionalism and could also inhibit self-reflection and openness to learning. Formally acknowledging contextual factors that impact on students' preparation for practice throughout the degree, including in particular, in placement finding discussions with students and during placement, aligns well with a critical approach to the practice of social work.

Many workplace cultures and environments do not meet an idealised version of social work practice. Yet, we do not want students to lose the vision of ethical, socially just and human-rights-based practice. Preparing them for this practice requires students to engage in diverse and complex work in a neoliberal environment (Morley \& Dunstan). It also requires social work supervisors and educators to make an effort to properly support the students in their learning and help them to critically unpack circumstances and contexts that are less than ideal. While we present students with ideas that learning can happen anywhere, and that the perfect placement is a myth, the preparation for ensuring they can work in complex environments with a strong social work identity needs to be explicit through the curriculum in order to facilitate their field education journey utilising critical reflection and liaison support (Morley \& Dunstan, 2013).

The original and extended model therefore present a useful tool for student's consideration and discussion of their own circumstances and their pathways towards becoming a professional social worker, allowing students to distinguish more clearly on areas they do have control over versus areas outside of their control as a student, learner and developing practitioner.

Further research could explore the application of this updated model early in the degree and the impact this has on student preparation for practice and confidence for field education. Social work educators could engage with students about suitability for social work practice early in the degree by including the model in subject 
outlines and content. Other research could explore active engagement of students in the shaping of assessment as a way of promoting professional integrity and student confidence.

\section{Limitations}

While the survey response rate was deemed appropriate in relation to the overall target population, the results cannot be generalised due to the relatively low numbers and the limited context of one university. While surveys do not achieve in-depth knowledge, for this study it was decided that an online survey tool was most appropriate to encourage honest feedback through anonymity and confidentiality.

Moreover, the survey tool did not distinguish between suitability issues impacting field education and graduate practice, but asked about suitability for either in the same question, as field educators, in an earlier phase of the research, spoke about suitability issues impacting field education and graduate practice in a global sense. Thus, aspects specifically relating to the summative assessment of suitability for field education have not been considered. Future research could help with further clarification, interpretations and understandings regarding students' suitability for field education and the larger question of suitability for professional practice.

The model includes the consideration of cultural perspectives. Further exploration is needed to explore how cultural contexts and aspects of supervision might be defined and considered across countries and nations.

\section{Conclusion}

The findings from this research emphasise the importance of considering contextual factors and not only those internal to the student when addressing professional suitability concerns with students. The elements of the presented model are well acknowledged as relevant to field education and are commonly considered in preparing students for field education; however, the presented model is a practical tool for curriculum development and engaging in discussions about suitability for field education and suitability for professional practice between students, field educators and social work educators early in social work education. Utilising a visual tool to frame student professional suitability as a collaborative endeavour involving students, the field and the social work educators can actively engage students and facilitate professional integrity. Engaging with students early and respectfully in the evaluation of suitability for practice assists the professional growth of students. Ideally, discussing suitability with students needs to occur throughout the curriculum and well before placement, so that students are better prepared for field education and professional practice or, alternatively, better positioned to identify that social work practice is not something that they wish to pursue.

\section{References}

AASW. (2013). Practice standards 2013 (pp. 1-19). Canberra, ACT: Australian Association of Social Workers

Agllias, K., Howard, A., Cliff, K., Dodds, J., \& Field, A. (2015). Students' experiences of university and an Australian social work program: Coming, going, staying. Australian Social Work, 69(4), 468-480. doi:10.1080/0312407x.2015.1090464

Anderson, T., \& Kanuka, H. (2003). E-research: Methods, strategies and issues. Boston, MA: Pearson Education.

Basnett, F., \& Sheffield, D. (2010). The impact of social work student failure upon practice educators. British Journal of Social Work, 40(7), 2119-2136. doi:10.1093/bjsw/bcq012

Bogo, M., Regehr, C., Hughes, J., Power, R., \& Globerman, J. (2002). Evaluating a measure of student field performance in direct service. Journal of Social Work Education, 38(3), 385-401. doi:10.1080/10437797.200 2.10779106

Cleak, H., Hawkins, L., Laughton, J., \& Williams, J. (2015). Creating a standardised teaching and learning framework for social work field placements. Australian Social Work, 68(1), 49-64. doi:10.1080/031240 $7 X .2014 .932401$

Cleak, H., \& Wilson, J. (2019). Making the most of field placement (4th ed.). South Melbourne, VIC: Cengage Learning Australia.

Cook-Sather, A. (2006). Sound, presence, and power: "Student voice" in educational research and reform. Curriculum Inquiry, 36(4), 359-390. 
Croaker, S., Dickinson T., Watson, S., \& Zuchowski, I. (2017). Students' suitability for social work: Developing a framework for field education. Advances in Social Work and Welfare Education, 19(2), 109-124.

Egan, S., Waugh, F., Giles, R., \& Bowles, W. (2017). Authentic assessment: Partners in developing a web-based guide. Social Work Education, 36(6), 731-744.

Finch, J. (2017). "It's just very hard to fail a student": Decision-making and defences against anxietyAn ethnographic and practice-near study of practice assessment panels. Journal of Social Work Practice, 31(1), 51-65. doi:10.1080/02650533.2016.1158156

Furness, S., \& Gilligan, P. (2004). Fit for purpose: issues from practice placements, practice teaching and the assessment of students' practice. Social Work Education, 23(4), 465-479. doi:10.1080/0261547042000245053

Gair, S., \& Baglow, L. (2017). Australian social work students balancing study, work, and field placement: Seeing it like it is. Australian Social Work, 71(1), 46-57. doi:10.1080/0312407x.2017.1377741

Giles, R., Irwin, J., Lynch, D., \& Waugh, F. (2010). In the field: From learning to practice. Sydney, NSW: Oxford University Press.

Holmstrom, C. (2014). Suitability for professional practice: Assessing and developing moral character in social work education. Social Work Education, 33(4), 451-468. doi:10.1080/02615479.2013.847914

Homonoff, E. (2008). The heart of social work: Best practitioners rise to challenges in field instruction. The Clinical Supervisor, 27(2), 135-169. doi:10.1080/07325220802490828

International Federation of Social Work. (2014). Global definition of social work. Retrieved from https://www.ifsw.org/what-is-social-work/globaldefinition-of-social-work/

Lafrance, J., \& Gray, E. (2004). Gate-keeping for professional social work practice. Social Work Education, 23(3), 325-340. doi:10.1080/0261547042000224065

Liamputtong, P. (2009). Qualitative research methods (3rd ed.). Melbourne, VIC: Oxford University Press.

McNamara, J. (2013). The challenge of assessing professional competence in work integrated learning. Assessment and Evaluation in Higher Education, 38(2), 183-197. doi:10.1080/02602938.2011.618878

Morley, C., \& Dunstan, J. (2013). Critical reflection: A response to neoliberal challenges to field education? Social Work Education, 32(2), 141-156. doi:10.1080/026 15479.2012.730141

Olssen, M., \& Peters, M. A. (2005). Neoliberalism, higher education and the knowledge economy: From the free market to knowledge capitalism. Journal of Education Policy, 20(3), 313-345.

Parker, J. (2010). When things go wrong! Placement disruption and termination: Power and student perspectives. British Journal of Social Work, 40(3), 983-999. doi:10.1093/bjsw/bcn149

Razack, N. (2000). Students at risk in the field. In L. Cooper \& L. Briggs (Eds.), Fieldwork in the human services. Theory and practice for field educators, practice teachers and supervisors (pp. 195-204). Sydney, NSW: Allen \& Unwin.
Sussman, T., Bailey, S., Richardson, K. B., \& Granner, F. (2014). How field instructors judge BSW Student readiness for entry-level practice. Journal of Social Work Education, 50(1), 84-100. doi:10.1080/10437797. 2014.856233

Tam, D. M., Coleman, H., \& Boey, K. W. (2012). Professional suitability for social work practice: A factor analysis. Research on Social Work Practice, 22(2), 227-239. 